\title{
Enhancing the Credibility of Qualitative Method in Strategic Management Research
}

\author{
Marwan Al Qur'an
}

Catchphrases: Trustworthiness, Qualitative studies, Strategic management.

\section{INTRODUCTION}

it's been discussed that the form of research device impacts legitimately and altogether the nice, legitimacy and generalizability of commercial corporation look at maximum of the time and vital management inquire approximately (SM) specifically ((McGrath \&Brinberg, 1983). in addition, the advancement and imagination in studies shape and strategies have contributed substantially to the development of the field ofstrategic the board all in all, and normal enterprise technique especially (Kogut, 2001). anyways, many skilled global agency manner researchers contend that maximum actual research in worldwide enterprise strategyrelies on ballot evaluation as well as elective information which embody crucial problems as respects to the importance and wealth of knowledge the approach subjects in IB. In like way, they've called for rich clinical subjective contextual analyses to growth exhaustive comprehension of many convoluted, culturally diverse and technique related wonders which cannot be performed by using the ruling quantitative research techniques (as an example Boddewyn\&Iyer 1999; Craig and Douglas 2001). A case made through manner of (Ghauri\& Firth 2009)asserts that it's miles very useful and profoundly prescribed to utilize the contextual evaluation inquire approximately approach in exploring severa critical factors in key the executives inspect, for instance, worldwide corporation device (as the instance of the writer's ebb and waft have a look at version).

moreover, it has been located that the writing on inquire about strategies in IB has for the most component targeted around the issue of generalizability of the discoveries of multifaceted studies and unnoticed the issue of subjective and contextual investigation studies shape and techniques (Yang, Wang\& Su 2006). Discernibly, severa machine researchers have masses of mindfulness and records of the estimation of and importance of subjective and contextual

Revised Manuscript Received on December 30, 2019.

Dr. Marwan Al Qur'an, Abu Dhabi University, P.O Box 59911, Abu Dhabi, UAE, (Email: m_alquran@hotmail.com)

\begin{abstract}
This paper approach to make clear the way to enhance the reliability of subjective research in key administration. specifically, the paper examines methodological components of subjective information amassing and exam. moreover, the paper talks approximately splendid problems identified with subjective studies structure, as an example legitimacy, unwavering terrific and speculation. Thusly, this paper has made noteworthy methodological and hypothetical commitments to the writing on subjective studies in vital management.
\end{abstract}

investigation inquire approximately techniques in international commercial enterprise method. in any case, subsequent to no gadget subjective and contextual studies studies became visible in commercial enterprise diaries. finally, this paper expects to fill this obvious hollow in technique writing thru outlining a way to effectively strive precise contextual analyses in worldwide enterprise tool research using the case of the writer's ebb and waft contextual research explore which spotlights at the internationalization and far flung market selectionstratgey. specifically, the paper examines methodological additives of contextual research research plan and subjective information accumulating and exam. From the begin, the paper legitimizes the choice of subjective and contextual research approach. the second one precept a part of the paper subtleties the contextual research configuration, case selfdiscipline and the quantity of instances. The zero. 33 number one area clarifies the information accumulation and studies strategies and strategies. The fourth phase talks approximately nice problems identified with the contextual evaluation studies shape. At long closing, the cease is given in the path of the end of the paper.

\section{JUSTIFICATION FOR QUALITATIVE RESEARCH METHODOLOGY}

The exploration trouble "how do" and the precept question "what are" are clean as opposed to prescriptive, which require a hypothesis building method (inductive) instead of a hypothesis checking out one (deductive) (Perry 1998). In like manner, the interpretive worldview (inductive) is extra healthy than the positivist worldview (deductive) in mild of the fact that the examination is concerned about imagining the genuine universe of explored marvels in choice to giving measurable insights concerning the motive impact connections between elements within the analyzed wonders. moreover, the internationalization and outdoor market dedication manner is a totally multifaceted procedure (Atthirawong\&MacCarthy 2002; Carla 1994). therefore, the author's examination come to be alleged to growth a rich and thorough photograph concerning easy fulfillment elements and ranges engaged with the numerous preference strategies tried with the aid of the usage of Arabian organizations in deciding on the out of doors united states of america for their global obligations. Thusly, the most perfect approach to recognize and monitor the very complex segments of this way is getting within the brains of the organizations ${ }^{\text {ee }}$ chiefs and knowledge the process from their perspectives (Hassard 1993) and encounters (Smith \&Heshusius 1986).

Published By: 
within the ebb and drift inquire about, the subjective approach is the maximum useful approach for gaining access to pinnacle officers and their mentalities because it offers force and wealth within the amassed information that would keep away from and triumph over the essential boundaries of legitimacy and unwavering satisfactory in a social and hierarchical exam. except, it's miles progressively relevant when the examination goal is to investigate profoundly the strategies and components of world enterprise (Yeung 1995), just like the purpose of the creators' exploration. The subjective method empowers the scientist to realize the person encounters of humans greater profoundly and evidently than does the positivist method (Gummesson 2003; Patton 1987; Spencer. Et al. 2003). Its usage prepared with the reasonably modest style of cases analyzed and was endorsed while statistics received from each trouble modified into relied upon to assessment in complex manners and every assembly become a tale in its very very personal proper (Ticehurst and Veal 2000).

\section{JUSTIFICATION FOR CASE OBSERVE APPROACH}

A contextual research in the executives schooling is characterised as a "depiction of the board condition" (Bonoma 1985, p.203); even though, as an exam technique or technique it's miles portrayed as "an experimental request that explores a contemporary surprise with its authentic setting, specifically while the limits amongst marvel and setting not evidently obvious" (Yin 2003, p.13). specific methodologists portrayed the contextual research as an exam philosophy which relies upon broadly on interviews (Perry 1998). Contextual research is probably exploratory, enlightening or illustrative (Yin 1981; 2003), particularistic, image or heuristic (Merriam 1988) and preview, longitudinal, pre-put up, interwoven or comparable (Jensen and Rodgers 2001). As needs be, the classification of the chosen contextual analyses for the go with the float studies is exploratory as indicated via manner of Yin ${ }^{\text {ee }}$ typology (Yin 1981; 2003) due to the fact the exam embraced the inductive method looking for to consist of and expand new factors of the current-day speculation in the place of internationalization and some distance flung marketplace passage. The exploration's contextual investigations are heuristic (Merriam 1988) in light of the fact that they growth encounters and the facts of ranking directors in institutions in connection to the internationalization simple control, and near (Jensen and Rodgers 2001) whilst you don't forget that they have been selected purposively from numerous ventures and sizes to coordinate the discoveries via completing move-case exam and evaluation.

whilst all is stated in achieved, the contextual evaluation way modified into embraced inside the present exam for the few motives. Predominantly, contextual assessment method is the maximum fitting approach when the exploration trouble has a tendency to the problem of „how do ${ }^{\text {ee }}$ rather than ,how should ${ }^{e e}$ and, thusly, the inductive (speculation constructing) technique is required to cope with that exam issue (Perry 1998). at the give up of the day, the contextual research approach approach to make clear inductively the genuine setting of the marvels being inspected (illustrative) in place of developing regularizing fashions dependent on a speculation attempting out approach which portrays how the wonders need to exist (prescriptive). except, as indicated through Yin (2003, p.2) "the contextual investigation approach permits shops to preserve the complete and essential attributes of real occasions -, for example, human beings existence cycles, hierarchical and administrative methods,... ". The issue of the author's exploration changed into to research the problem of ,how do Arabian agencies efficaciously internationalize their commercial enterprise sports and choose their out of doors company sectors'. finally, the author endeavored to determine the constructed up examine hassle through getting true and interior and out records from chiefs of the chose institutions to increase a wealthy comprehension of approaches internationalization selections are made as a favored rule. therefore, finding out foreordained recommendations or theories as because of a deductive technique became now not the state of affairs of his exam. similarly, the contextual evaluation method is a sturdy ground for the hypothesis building method it truly is in reality appropriate for brand spanking new zones of research wherein little is concept (Eisenhardt 1989) or for refining the present day hypothesis and offering new headings for similarly studies (Stake 1994). At lengthy ultimate, it's far amazingly beneficial and particularly prescribed to utilize the contextual research have a examine device in exploring numerous important problems in worldwide industrial enterprise study, as an example, far off market passage forms (Ghauri\& Firth 2009).

\section{CASE OBSERVE RESEARCH LAYOUT}

As tested through Yin (1994; 2003) the contextual research configuration speaks to the exploration plan that aides the manner of statistics amassing, examination and understanding. 4 forms of contextual evaluation plans were proposed by using Yin (2003): (a) solitary case (all encompassing), (b) unmarried case (implanted), (c) numerous case (whole) and (d) numerous case (set up). at the start, the unmarried case configuration shows the sending of 1 contextual assessment and it is comprehensive while it consists of virtually one unit of exam or the case itself;whereas, it's miles inserted on the off danger that it coordinates increasingly complex subunits of investigation (Yin 2003). apparently, numerous case configuration alludes to directing a few contextual investigations or trials (Villard 2003; Yin 2003) and, it very well can be all encompassing at the off chance that it includes some entire instances in which each all encompassing case carries of only a single unit of examination. in any case, the implanted diverse case configuration consists of various installation cases wherein every inserted case contains severa devices of investigation (Yin 2003). The severa contextual evaluation configuration became the maximum turning into shape for the ebb and drift find out in slight of the reality that it changed into not proceeding to test hypothesis or to realize a completely unique and not unusual marvel as in the single case plan. Be that as it may, a crucial preference approach takes quite a while (Mintzberg, Raisinghani\&Theoret 1976) on this

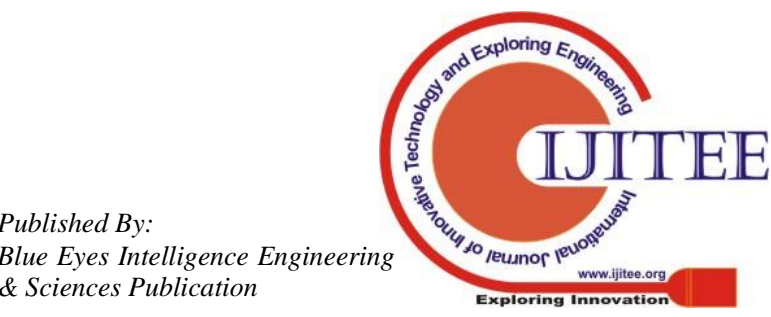


manner, due to time and other research asset boundaries, it's miles tough to depend upon one unmarried company case and watch the internationalization and far off marketplace choice approach from starting to fruition.

To located it plainly, the various case configuration have become favored over the single case shape since it gave hearty and thorough grounds to exceptional first-rate research have been given from the triangulation of proof contrasted and unmarried case plan (Eisenhardt, 1989; Parkhe 1993; Yin 2003). in addition, the evidence disconnected from precise case research is regarded as an increasing number of floor-breaking and all the greater convincing

(Herriott\& Firestone 1983) and the method is a beneficial equipment to choose up statistics into all parts of the way an affiliation has a tendency to complex key primary management (Ulaga\& Sharma 2001).

\section{4a. cases choice}

experienced scientists have set up ordinary know-how which advocate firmly that the determination of contextual investigations must be made depending on ,theoretical samplingee and not founded on ,random samplingee similar to the case with assessment inquire about (Eisenhardt 1989; Glaser and Strauss 1967; Patton 1990; Perry 1998; Yin 2003). As indicated by means of using Glaser and Strauss (1967 p.forty five) hypothetical examining is "the technique of statistics accumulation for producing speculation in which the expert together gathers, codes, and investigations his records and chooses what facts to acquire straightaway and wherein to find out them, in order to accumulate his hypothesis because it rises". Yin (2003, p.47) contended unequivocally that various times need to be taken into consideration as numerous analyses and now not distinct respondents in an outline and times need to be selected depending on replication cause and now not based on inspecting reason. sooner or later, each case either predicts comparative effects (strict replication) or predicts inverse effects for predicable motives (hypothetical replication). Patton (2003) furnished the concept of ,practical samplinge supplying that contextual analyses ought to be chosen from amongst capacity instances that are information rich and supply the scientist with profound facts and comprehension about the exploration hassle. along those traces, he recognized 16 extraordinary strategies of planned examining for case willpower of which 4 systems were used in the momentum inquire about.

The proposed various case configuration emerge as chosen dependent on Patton's mix or blended planned analyzing approach (Patton 2002) thru utilizing some sorting out processes (foundation, lodging, and energy inspecting technique). for this reason, organizations had been purposively decided on and they have been records rich, open, proximal, extensive, driving and entrenched Saudi assembling and expert assist employer which built up one of a kind seaward activities. The manner concerning the hypothetical willpower of contextual investigations is delineated in parent 1 .

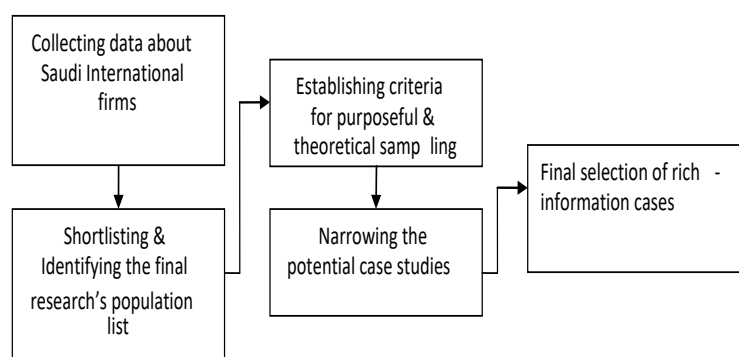

Figure 1: The selection process of case studies

\section{4b. Data Collection Methods and Techniques}

Contextual evaluation research can comprise every subjective and quantitative information and ongoing methodologists have top notch a few techniques of information accumulation of contextual research primarily based-take a look at out but it is not crucial to use those strategies (Bogdan \&Biklen 1982; Patton 1990; Yin 2003). those strategies consist of (1) interviews, (2) poll, (three) chronicled statistics, (four) direct perception, (five) member belief, (6) documentation and (7) physical relics. As cited with the aid of way of Bogdan \&Biklen (1982) meetings can be applied both as a significant strategy for statistics gathering in subjective studies or in mix with distinct wellsprings of statistics, for example, archive examination, perception or awesome strategies. in this manner, the ebb and go together with the glide scientist trusted interior and out meetings as an crucial data source and approach in mild of the reality that the great majority of the explored four internationalization alternatives, in the selected Saudi timevenerated groups, had been made some time again because of this it was hard to discover critiques or chronicled statistics identified with these choices within the greater part of the embraced instances contemplates, a circumstance perceived by using Mintzberg, Raisinghani\&Theoret (1976). moreover, direct belief, member perception and the interrelated physical curios were unfeasible, out of achieve and difficult to be carried out within the ebb and waft inquire about. ultimately, those desire approaches have been actually geared up to be investigated after quit result and the professional, on this manner, have to be challenge to precious information assets related to up close to and private, interior and out conferences inside the momentum research to consolidate the contextual evaluation database for each unmarried case and for the most detail triangulate the meeting statistics. distinct assets apart from archive audit have been: (1) a ballot which changed into hooked up after the assembly instructions, (2) field notes that have been taken at some stage in the visits to the chosen 5 case companies and at a few degree inside the assembly direction, (three) internet property reachable on the affiliation's net website online which contained statistics about the corporation's revel in and worldwide obligations (4) follow-up smartphone and e mail contacts made consequent to the meetings to provide an reason for meetings related facts and get more information about the exploration problems. basically, the top to backside 


\section{Enhancing the Credibility of Qualitative Method in Strategic Management Research}

meetings were led the use of a semi-prepared meeting guide in light of the reality that the quarter of internationalization and far flung marketplace phase selections is a generally new sector of studies and the analyst has exquisite meeting abilties to cope with the assembly manner viably (Cavana, Delahaye\&Sekaran 2000). except, one of the powerful traits the ebb and go along with the float research became investigating the examination issues clearly as it gave possibilities to both questioner and interviewee to speak approximately the factors in more detail, permitting the interviewees to uninhibitedly and without a doubt express their views, convictions and contemplations (Lofland\&Lofland 1995; Mathers, Fox \&Hunn 1998;). also, considering that severa contextual analyses have been led and each contextual research taken into consideration as a solitary trial (Yin 2003), the adaptability and versatility which recognize semi-prepared meetings accredited converting and adjusting of inquiries addresses whilst required to increase wealthy, stable, valid and authentic statistics thru coordinating the assembly technique and posing a similar inquiry in numerous manners to clarify a similar problem (Mathers, Fox \&Hunn 1998). All in all, in view of the preceding communicate, in each one of the directed times, interior and out conferences were led at unique lessons with the available and maximum gifted rating directors who took an hobby altogether within the internationalization and far off show off determination technique.

\section{4c. Contextual research information collection approaches}

The facts amassing strategies for the contextual studies protected crucial degrees. The number one level started with planning and putting in vicinity the contextual research convention pursued by the accumulation of information from the sector. those stages are clarified inside the following sub-headings.

\section{4c.1. Contextual investigation Protocol}

Contextual investigation conference became prepared earlier than the facts amassing machine and integrated the assembly tool, but furthermore the strategies and activities required to are searching for after in using the tool. The contextual investigation conference installation the complete data accumulating technique and it's far seemed as a fundamental piece of the contextual research inquire about. As proposed with the resource of Yin (2003, p.69), the contextual analysis conference for the drift studies consolidated four primary segments as pursues:

- An compare of the contextual investigation studies project (desires, troubles, difficulty topics being examined).

- area approach (getting access to locations, wellsprings of records, timetable of data collecting physical activities).

- $\quad$ Case look at questions (explicit inquiries that the expert need to undergo in mind at some stage in facts accumulation).

- A control for contextual research file (plot, function for the account).

\section{4c.2. method of amassing the sphere information} and alternatives of the semi-prepared assembly method for

The facts gathering method started out in overdue June, 2009 and it pursued the policies encouraged via Dick (1999):

1. touch the respondents.

2. give an explanation for the incentive inside the back of the exploration challenge to respondents.

three. set up wonderful truthful association with the respondents.

four. determine a date, time and putting for the assembly path.

At the start, smartphone contact become made with the prominent most important and most gifted ranking administrators engaged with the internationalization preference. The cellphone discussions saved going 5-10 mins and meant to make clean the exam motive and questions to individuals and decide a date, time and scene for the meeting sessions. Given that each one contributors have been heads of businesses and had been occupied, the cited assembly time became lengthy (greater than hours to three hours), there has been an intentional business enterprise now not to place any weight on them concerning the meeting sport plans; henceforth, the conferences have been directed at a date, time and scene beneficial and appropriate for them. The contributors were reached through cellphone and a concurred date, time and the placing emerge as set for the assembly durations. Masterminded dates and times were affirmed with the individualse man or woman secretaries by way of phone or 3 days previous the meeting dates. The cellphone contacts with the ranking administrators made a neighborly air between the scientist and the individuals and contributed basically to the accomplishment of the assembly sessions and the contextual evaluation field strategies. All pinnacle to backside conferences had been led over a time of one / four of a 12 months.

\section{STUDYING CASE LOOK AT RECORDS}

by means of and big, subjective data examination alludes to the excellent quantity of phrases had been given via meetings or perceptions which require portraying and abridging and on this way the analyst needs to search for connections between one-of-a-kind subjects that have been risen at a few level in the studies system to reply to the exploration questions (Lacey and Luff 2001). Miles and Huberman (1984; 1994) proposed a 3-diploma subjective information studies method which can be carried out to internal and move-case examinations of the subjective facts in outstanding contextual analysis inquire approximately. This method consists of the accompanying ranges:

- $\quad$ records decrease

- information display

- conclusion drawing and affirmation

facts decrease alludes to the route of choosing, centering, rearranging, condensing and converting over the data of composed discipline. As a extremely good factor of this level, the records requires condensing and coding subsequently classifications and subjects should be made as 
in line with the foreordained studies questions.

information display as a next degree consists of showing the faded statistics in composed and low cost form to permit the analyst to reach at picks approximately research troubles. word or diagrammatic structure such stream outlines, tables and distinct designs can be applied to gather and orchestrate the facts. Likewise, a community can be carried out for dissecting examples of reactions to the examination query.

end drawing and affirmation otherwise called the elucidation level and it suggests giving importance and experience to the examined information thru seeking out an attractive examples within the statistics.

two precept levels of exam are prescribed for severa contextual research look into, this is., indoors case research and skip case research (Eisenhardt 1989; Yin 2003). internal case research includes breaking down the accrued subjective and quantitative records of every contextual evaluation freely after which the professional closes the discoveries approximately the exam issues for every person case. Yin (2003, pp.111-a hundred and fifteen) depicted three important investigative methodologies for interior contextual assessment examination: 1. depending on the hypothetical recommendations of the exploration; 2 . Characterizing and finding out rival or differentiating clarifications and three. building up a nitty gritty depiction or document for every unmarried contextual analysis. in addition, Yin (2003) prominent the instance coordinating method as one of the most appealing explanatory systems to be utilized in internal case research. The gadget includes contrasting exactly based examples and expected or anticipated one. In like way, every, the contextual investigation record and example coordinating structures have been applied inside the writer's exploration.

The 2nd proposed phase of information research for severa state of affairs observe research identifies with movecase exam which shows scanning for cross-case designs. Eisenhardt (1989, pp.540-541) proposed 3 enormous crosscase scientific methodologies. the first is to classify cases depending on unique measurements and in a while search for likenesses and contrasts the various gathering of cases. the second is to choose instances and rundown the likenesses and contrasts between them. The final method is to separate the information thru information supply, as an instance, one analyst takes a shot at communicate with statistics, at the same time as some other surveys poll records. Taking the whole thing into attention, inner case and pass-case investigations have been completed in breaking down the records of the ebb and go together with the waft look at. similarly, the example or subject matter coordinating was contrasted and the rose topics with examples were given from the writing survey. In circulatecase exam, classifying the contextual investigations relying at the sort of enterprise, as an example, fabricating organizations versus control companies and pursued thru look for similitudes and contrasts amongst those classifications changed into received as a logical technique for pass-case design. moreover, the three-degree data exam system (Miles and Huberman 1984; 1994) became utilized in dissecting the meeting records of contextual investigations.

\section{THE NICE OF CASE STUDY RESEARCH LAYOUT\& RESULTS}

learning thoroughness is a essential section of all examination in wellknown and of contextual investigation discover mainly (Miles and Huberman 1984; 1994; Yin 2003). in this manner, the creator agreed to sure set up standards and done smart evaluation in the course of the contextual research research structure, information accumulation and information exam to guarantee the thoroughness, credibility and reliability of the exploration discoveries. these low priced exams fused legitimacy, constancy/unwavering nice and transferability/speculation.

\section{6a. Legitimacy}

Legitimacy alludes to the exactness and reliability of devices, data and discoveries in the exploration (Bernard 2000). There are three principle forms of legitimacy which require to be assessed in any exploration, this is, develop, interior and outer legitimacy.

\section{6a.1. construct Validity}

construct legitimacy alludes to putting in proper operational measures for the hypothetical thoughts being explored by way of connecting the statistics accumulation questions and measures to investigate questions and speculations (Rowley 2002; Yin 2003). develop legitimacy became glad within the momentum postulation with the resource of: (1) structuring contextual studies conference inquiries and posing to inquiries during the meeting periods which viably stuck a miles achieving and wealthy comprehension approximately the exploration crucial problem essential to the internationalization and a ways off marketplace desire method (Rowley 2002; Yin 2003), (2) retaining up the chain of evidence via making certain the supply of the world manual for records accumulation, the contextual analysis notes and giving sufficient illustration for the scenario file to the proof contained in the database (Bourgeois \&Eisenhardt 1988; Rowley 2004; Yin 2003), in the end (3) the usage of one among a kind wellsprings of evidence (triangulations, for instance, top to bottom meetings, surveys and data (Bourgeois \&Eisenhardt 1988; Rowley 2002; Yin 2003).

\section{6a.2. inner Validity/Credibility}

The terms believability and inner legitimacy were applied reciprocally within the writing (Byrne 2001) and that they infer that the professional desires to discover built up connections amongst needy and self sustaining elements (Yin 2003). In cause of fact, the inner legitimacy is wanted and applied in illustrative or causal investigations and no longer inside the photo or exploratory studies similar to the case inside the author's exam (Yin 2003). however, the writer fulfilled this foundation by using utilising the instance coordinating through coordinating and differentiating the superior topics during the statistics examination with the constructed up subjects or instance within the leaving writing audited (Bourgeois \&Eisenhardt 1988; Rowley 2002; Yin 2003). 


\section{Enhancing the Credibility of Qualitative Method in Strategic Management Research}

\section{6a.three. hypothesis/external Validity/Transferability}

terms, as an example, hypothesis, generalizability, outer legitimacy (Yin 2003), transferability and materialness (Byrne 2001) were flawlessly applied inside the writing. through and massive, speculation/outer legitimacy/transferability alludes to the diploma to which the exploration's discoveries can be summed up beyond the activate contextual research and applied to 1-of-a-kind settings or to high-quality instances of the examination whole populace (Byrne 2001; Yin 2003). for the reason that "the motive for the contextual evaluation isn't to speak to the world, however to talk to the case" (Stake 1994, p. 245) and contextual investigations want to be selected depending on „theoretical samplingee and now not on „,random samplingee likewise with quantitative studies (Eisenhardt 1989; Glaser and Strauss 1967; Patton 1990; Perry 1998; Yin 2003), the "expository generalizatione is applied to contextual evaluation inquire about and no longer "measurable generalization $^{\text {ee }}$ as in quantitative studies which manages huge haphazardly selected check (Yin 1994; 2003). Explanatory speculation intends to what diploma are the discoveries of the directed contextual analyses imitated and constant (Yin 2003). outside validity or generalizationwas performed within the modern-day have a look at through the usage of: (1) the use of replication good judgment inside the a couple of case layout (Yin 2003) in which the findings from the chosen instances had been replicated (Yin 1994;

2003); (2) adopting the functional sampling in deciding on the case research (Patton 1990), (three) writing facts-rich case check description or file for the data of every case study (Byrne 2001) and ultimately (4) by means of the multiple case look at format itself in which all decided on instances had been businesses from one country (Saudi Arabia), and represented the two vital industries (production and provider).

\section{6a.four. Reliability/Dependability}

Reliability is also referred to as dependabilityin the literatureand it illustrates to which degree the tool is solid and everyday with measuring the idea to allow repeating the equal studies the usage of the same method, pattern and the information series produced that permits you to advantage the same consequences of these previous take a look at (Sekaran 1984). Reliability changed into executed within the current-day studies via: (1) the use of case check protocol (Yin 2003) wherein all the chosen case research (taking part groups) and all contributors (informants) have been subjected to the identical collection of entry and exit techniques and interview questions (Bourgeois \&Eisenhardt 1988) and (2) intensive documentation of techniques and suitable recording preserving (Byrne 2001; Bourgeois \&Eisenhardt 1988; Yin 2003). moreover, gathering the information through in-depth interviews with the most knowledgeable senior managers (informants) who participated within the internationalization choice will growth notably the reliability of the findings of the research (Huber \& strength 1985; Papadakis, Lioukas\& Chambers 1998).

\section{CONCLUSION}

for the reason that the literature on research methodologies in strategic manage (SM) has especially centered on quantitative studies along side the trouble of generalizability of the findings of move-cultural studies and omitted the problem of qualitative and case look at studies layout, this paper aimed to fill this evident hole in SM literature thru illustrating how to undertake more than one case studies in worldwide business employer method research the use of the example of the author's case look at studies which focused on the internationalization and overseas market approach. As a give up end result, the modern paper has made a great contribution to the literature via demonstrating how to properly conduct a case study research in strategic control. it is able to be used as a sensible methodological guide for SM researchers inquisitive about challenge case check studies. The paper additionally has added to mild the advantages of the qualitative and case have a look at studies approach. firstly, the more than one case observe approach enabled the researcher to bring together the whole vital understanding and stories of desire-makers concerned within the internationalization method. Secondly, the purposively and theoretical selection of the observe instances from amongst precise industries and sizes enabled the researcher to evaluate and evaluation the findings of those precise instances and broaden a popular model for a fulfillment distant places marketplace choice approach. eventually, the purposive and in-intensity interviewing of the maximum knowledgeable choice-makers provided credible and treasured data about the nature of the foreign marketplace choice procedure.

\section{REFERENCES}

1. Amaratunga, D., Baldry, D., Sarshar, M. \& Newton, R. 2002, 'Quantitative and qualitative research within the constructed surroundings: utility of 'blended' studies technique', paintings look at, vol. 51, no. 1, pp. 17-31.

2. Bernard, H. R. 2000, Social studies strategies: Qualitative and quantitative techniques, Sage booklet, Inc, Thousand alright.

3. Boddewyn, J. J. \&Iyer, G. 1999, 'global-corporation research: past deja vu', control global evaluate, vol. 39 , no. 2 (specific hassle), pp. 161-184.

4. Bogdan, R. C. \&Biklen, S. ok. 1982, Qualitative research for training: An introduction to precept and strategies, Allyn and 1st Baron Beaverbrook, Boston.

5. Bonoma, T. V. 1985, 'Case studies in advertising and marketing: possibilities troubles and a method', journal of marketing research, vol. 22, no. 2, pp. 199-208.

6. Bourgeois, L. J. \&Eisenhardt, ok. M. 1988, 'Strategic choice way in immoderate pace environments: 4 times inside the microcomputer enterprise', control technological know-how, vol. 34, no. 7, pp. 816835 .

7. Brown, H. 1988, Rationality, Routledge, London.

8. Bryman, A. 1990, research techniques and business enterprise studies, Unwin Hyman, big apple.

9. Bryne, M. M. 2001, 'comparing the findings of qualitative research', AORN journal, vol. Seventy three, no. 3, pp. 703-706.

10. Carla, k. 1994, 'in which inside the international to make it?' international commercial enterprise, vol. 7 , no. 2 , pp. fifty two-fifty five.

11. Cavana, R. Y., Delahaye, B. L. \&Sekaran, U. 2000, implemented studies: Qualitative and quantitative strategies, John Wiley \& Sons Australia, Ltd, QLD. 
12. Craig, C. S., \& Douglas, S. P. 2001, "conducting worldwide advertising research in the twenty-first century". international marketing assessment, vol. 18, no. 1, pp. 80-ninety.

13. Dick, B. 1999, Rigour without numbers: The functionality of dialectical strategies as qualitative research system, 3 edn, Interchange, Chapel Hill, Qld.

14. Eisenhardt, k. M. 1989, 'constructing theories from case look at research', The Academy of control overview, vol. 14, no. four, pp. 532-550.

15. Ghauri , P.N \& Firth, R. 2009, " The formalization of case look at research in global business employer", der market, vol. forty eight, pp. 29-forty.

16. Glaser, B. G. \& Strauss, A. L. 1967, the discovery of grounded concept: strategies for qualitative research, Aldine Publishing agency, big apple.

17. Gummesson, E. 2003, 'All studies is interpretive', The magazine of business and business advertising, vol. 18, no. 6/7, p. 482 .

18. Hassard, J. 1993, Sociology and enterprise concept: Positivism, paradigms and postmodernity, Cambridge university Press, Cambridge.

19. Herriott, R.E., Firestone, W.A. 1983, "Multi-internet web page qualitative coverage research: optimising description and generalisability", instructional Researcher, vol. 12, pp.14-19

20. Huber, G. P. \& energy, D. J. 1985, 'studies notes and communication retrospective reviews of strategic-level managers: suggestions for developing their accuracy', Strategic management magazine, vol. 6 , no. 2, pp. 171-one hundred eighty.

21. Jensen, J. L. \& Rodgers, R. 2001, 'Cumulating the highbrow gold of case look at studies', Public administration overview, vol. 61, no. 2 , pp. 235-260.

22. Kogut, B. 2001, "Methodological contributions in worldwide busines organization andthe route of educational studies hobby". In A Rugman, \& T. Brewer (Eds.), The Oxford manual of international business, united kingdom: Oxford university Press, pp. 785-817.

23. Lacey, A. \& Luff, D. 2001, Qualitative statistics evaluation Retrieved: December 25, 2004, from http://www.Trentfocus.Org.uk/resources/Qualitativepercent20Datap. C20Analysis.Pdf.

24. Lofland, J. \&Lofland, L. H. 1995, Analysing social settings: A guide to qualitative statement and analysis, 3 edn, Wadsworth Publishing organisation, Inc, Belmont, California.

25. McGrath, J. E., \&Brinberg, D. 1983. "external validity and the research technique: A comment on the Calder/Lynch communicate". journal of purchaser research, vol.10, no.1, pp.115-124.

26. Mathers, N., Fox, N. \&Hunn, A. 1998, the usage of interviews in a studies assignment. Retrieved: December 25, 2004, from http://www.Trentfocus.Org.uk/resources/Qualitativepercent20Datap. C20Analysis.Pdf.

27. Merriam, S. B. 1988, Case examine research in schooling: A qualitative technique, Jossey-Bass, San Francisco.

28. Miles, M. B. \& Huberman, M. A. 1984, Qualitative facts assessment A sourcebook of latest strategies, Sage courses, Newbury Park, Calif.

29. Miles, M. B. \& Huberman, M. A. 1994, Qualitative statistics assessment: An stepped forward sourcebook, 2 edn, Sage courses, Newbury Park, California.

30. Mintzberg, H., Raisinghani, D. \&Theoret, A. 1976, 'The form of "unstructured" selection device', Administrative technology Quarterly, vol. 21, no. 2, pp. 246-275.

31. Papadakis, V., Lioukas, S. \& Chambers, D. 1998, 'Strategic choicemaking strategies: the position of control and context', Strategic management magazine, vol. 19, no. 2, pp. 115-147.

32. Parkhe, A. 1993, 'Messy research, methodological predispositions and concept development in global joint ventures', Academy of control review, vol. 18 , no. 2 , pp. $227-268$

33. Patton, M. Q. 1987, creative evaluation, 2 edn, Sage ebook, Newbury Park, California.

34. Patton, M. Q. 1990, Qualitative evaluation and studies techniques, 2 edn, Sage publication, Newbury Park, California.

35. Patton, M. Q. 2002, Qualitative evaluation and studies strategies, 3 edn, Sage guide, Thousand o.k., California.

36. Perry, C. 1998, 'approaches of a case have a examine method for postgraduate research in marketing', european journal of marketing, vol. 32, no. nine/10, pp. 785-802.

37. Rowley, J. 2002, 'the use of case research in studies', control studies news, vol. 25, no. 1, pp. sixteen-27.

38. Sekaran, U. 1984, research techniques for managers: A expertiseconstructing technique, John Wiley \& Sons, Inc, the big apple.

39. Smith, J. okay. \&Heshusius, L. 1986, 'final down the communique: The stop of the quantitative-qualitative debate among instructional inquires', instructional Researcher, vol. 15, no. 1, pp. four-12.
40. Spencer, L., Ritchie, J., Lewis, J. \& Dillon, L. 2003, first-class in qualitative evaluation: A framework for assessing studies evidence. Retrieved: $\quad$ December 25, 2004, from http://www.approach.Gov.uk/documents/pdf/Quality_framework.Pdf.

41. Stake, R. E. 1994, 'Case research', in N. k. Denzin\& Y. S. Lincoln, (eds.),

42. guide of qualitative studies, Sage courses, Thousand very well, California, pp. 236-247.

43. Ticehurst, G. \& Veal, A. 2000, enterprise research strategies: A managerial approach, Pearson schooling Pty constrained, Frenchs forest, Australia.

44. Ulaga, W. \& Sharma, A. 2001, 'complicated and strategic choice making in enterprise: Implications for personal selling and sales control', industrial marketing management, vol. 30, no. 5, pp. 427 440

45. Yang, Z, Wang, X, Su, C. 2006, " A evaluate of studies methodologies in international industrial corporation", international enterprise review, vol. 15, pp. 601-617

46. Yeung, H. 1995, 'Qualitative personal interviews in global enterprise research: a few classes from a have a look at of Hong Kong transnational organizations', global enterprise assessment, vol. 4, no. three, pp. 313-339.

47. Yin, R. k. 1981, 'The case check disaster: some answers', Administrative technology Quarterly, vol. 26, no. 1, pp. Fifty eightsixty five.

48. Yin, R. ok. 2003, Case take a look at studies: layout and techniques, three edn, Sage guide, Thousand okay, California. 